\title{
TOWARDS ONTOLOGY SOLUTIONS FOR ENABLING INTEROPERABILITY IN VIRTUAL ENTERPRISES
}

\author{
Raffaello Lepratti, Ulrich Berger \\ Brandenburg University of Technology at Cottbus, Chair of Automation Technology \\ D-03013 Cottbus, GERMANY [lepratti, ulrich-berger]@aut.tu-cottbus.de
}

\begin{abstract}
Virtual Enterprises (VE) are characterised by a multi-directional continuous information flow between all their geographical and structurally distributed members. Therefore, a fluent information flow has to be guaranteed. Unfortunately, various common communication problems among humans, among machines as well as between humans and machines normally arise and endanger significantly the interoperability between the VE members. In this paper different considerations concerning essential requirements for an effective collaboration among humans and between humans and machines are described. It is especially outlined, how ontology networks could contribute to overcome these problems. For this reason a prototype will be presented and its function and structure described. Finally, also consideration about its further enhancements are underlined.
\end{abstract}

\section{INTRODUCTION}

Virtual Enterprises (VE) differ from common enterprises by their organizational constructs consisting of a set of small globally geographic single organizational entities. Despite the spread location of the organization partners, these form a collaborative environment and co-operate together in order to achieve a common goal. Therefore, VE should be called Networked Enterprises (Gebauer et al., 1998).

For external observers, these networks often appear as whole, real enterprises. However, they consist of several legally autonomous parts -the network nodeswhich could be added and removed to the network according to changes in customer requirements and environmental dynamics. In a global market situation like the today's one, in which enterprises must continuously perform in order to compete and increase market share, VE represent the right answer for aiming at these targets.

Within the VE, a lot of actors collaborate together. Human and machines from different geographic areas are continuously in contact. Due to disparate cultural and lingual features of whole participating groups and, at the same time, due to the use of incompatible applications running on heterogeneous manufacturing systems numerously problems arise within the communication among humans, machines as well as between humans and machines endangering their interoperability. Figure 1 illustrates the intern information exchange among agents of a single network node. 


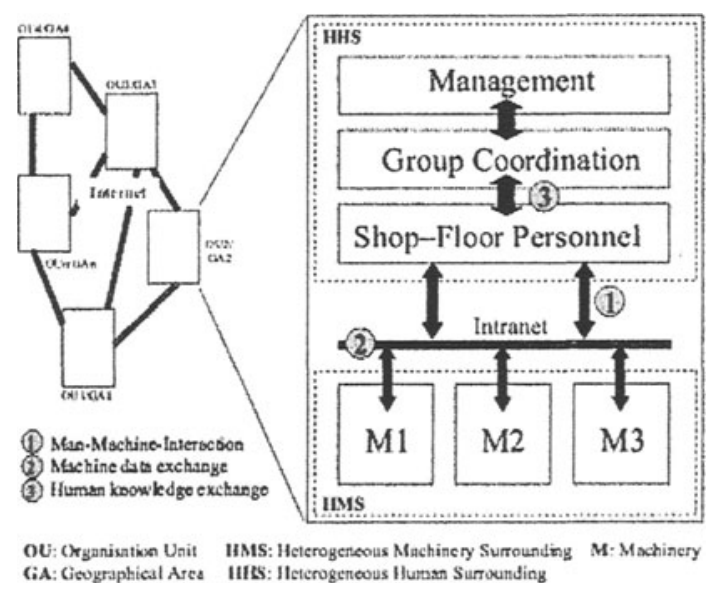

Figure 1 - Course structure of VE units

The guaranty of a safe information flow, such as knowledge and data exchange, presupposes the use of powerful tools, which allow the management of different types of information with different levels of representation form, performance and functionality (Sowa, 2000) (Guarino, 1994).

With emerging technologies like the Internet and the World Wide Web, the use of new IT technology plays a growing and crucial role promising benefits for VE in maintaining the relationships between all participant agents, and supporting their collaboration over geographical distances and across different time zones.

In addition, VE's are subject to a rapid structure change more than other kind of enterprises, due to the increased fluctuation of their actors and the constantly need to introduce new technologies or convert old technologies in new ones. In such a context, the knowledge retrieval of many years experiences still represents the most profitable knowledge basis. At the same time, the steady technological progress stresses the importance to develop new tools for allowing data and knowledge store as well as retrieval making this crucial factor for market competition.

In this paper some significant, already performed R\&D projects will be mentioned (section 2) and requirements for an effective collaboration among humans, machines and between humans and machines will be considered. Then, it is pointed out, how ontologies, particularly linguistic ones, could meet these requirements (section 3). Describing our ideas for a software architecture of a natural language interface it will be outlined, how ontology networks can be applied (section 4). First experimental trial tests within a prototype are finally reported as well as future research work steps are presented (section 5).

\section{PAST RESEARCH}

The complexity and large scope of the problem concerning the difficult interoperability in VE has involved numerous academic and industrial research groups in trying to establish new standards for improved communication both between VE actors. (Zarli et al., 1997). 
As a first step here it is necessary to distinguish between the following forms of interoperability (see Figure 1): (i) Human Knowledge Exchange, (ii) HumanMachine-Interaction and (iii) Machines Data exchange. For each of the fields above a rich number of research projects has been performed. The most significant will be described shortly as follows.

Standard interaction methodologies for machine data exchange, like STEP (STandard for Exchange of Product data) (Fowler, 1995), allow the expression of the whole information required for a product during its life-cycle. STEP is nowadays a well-known standard for real world product information modeling, communication and interpretation. With STEP, exchange and sharing of full product data semantics between actors is possible.

Also CORBA (Common Object Request Broker Architecture) (OMG, 1995) standard specified by the OMG (Object Management Group) is already an interesting solution to increase communication and interactivity levels between VE partners thanks to full applications interoperability mechanisms. CORBA provides neutral -both platforms and languages independent- communication between remote applications based on object oriented distributed technology, allowing different clients and/or servers connected within a network to live as individual entities able to access to the information they need in a seamless and transparent way.

The PSIM project (a Participative Simulation environment for integrated Manufacturing enterprise renewal) (Van Eijnatten et al., 2002) is part project and European version of the Japanese pilot project HUMACS (HUman-Machine Coexisting Systems) (Yamatake, 1996). It is an Information Society Technology (IST) project and focuses on the improvement of man-machine-interaction aiming at the active participation of both specialized staff, management and production personnel as well in assembly operations by means of developed and pilotdemonstrated simulation environment. Particularly, the attempt to involve stakeholders with different linguistic and professional qualification and tools with disparate standard communication languages is interesting.

The OntoSeek (Guarino et al., 1999) project is a system designed for contentbased information retrieval from online yellow pages and product catalogues. A combination of arbitrary natural-language terms for accurate resource descriptions in encoding phase and terminological flexibility in the formulation of queries, due to a process of ontology-driven semantic matching between queries and resource description, allows a content-based matching mechanism and access to the Web.

Further significant projects are The KL-ONE Language (Woods et al., 1992) and the SHARE (McGuire et al., 1993).

\section{THE ONTOLOGICAL ROLE}

Communication between VE agents, both humans and machineries need a shared understanding of a specific knowledge and data domain, that is acknowledged by all participants, in order to guaranty the same information cognition, avoiding, so, semantic misunderstandings. Unfortunately, the whole agents communicate at different expression levels, endangering the harmonically interoperation among themselves. According to R. J. Brachman (Brachman, 1979) one can distinguish diverse forms of Knowledge Representation, which could be classified into five 
different levels: (i) the Implementational -level of data structure- (including i.e. binary codes), (ii) the Logical -level of symbolic logic- (regarding to use of logical operators, like these of the Boolean logic, within binary codes), (iii) the Epistemological -the level for defining concept types- (concerning to the understanding of word forms, i.e. a person name), (iv) the Conceptual -level of semantic relations- (the understanding of word meanings) and (v) the Linguistic Level -level of arbitrary concepts, words- (i.e. all natural languages). The first three levels impose an arbitrary semantic interpretation of knowledge, while the latter two permit a subjective one. In spite of well-defined knowledge representation levels, however, among members of the same level there could be various, for the whole context inconsiderable, but for the particular one significantly differences of expressiveness. Thus, in case of VE, all machines communicate at the logical level, even if using different program languages, as well as humans at linguistic one, even if having various expression shadings, due to multilingual and cultural dissimilarity, as well as qualification divergences resulting from different professional educations and work experiences.

What we need for all VE agents is an effective commitment among them, which allows us to constrain or at least to approximate the intended meaning of specific knowledge forms - of a specific language- to a predefined model, consequently standardizing and formalizing the information content and reducing at the same time the danger of misunderstandings in the knowledge sharing process. For this purpose N. Guarino (Guarino, 1994) revised Brachman's theory and added a further level: The Ontological one - just the level of constrained meanings. In (Guarino, 1997) he resumed various definitions for ontology recognizing in the Gruber's one, the most effective one. In (Gruber, 1995) T. R. Gruber gave the following definition of ontology: "The ontology is a specification of a conceptualization" and N. Guarino with P. Giarretta in (Guarino et al., 1995) proposed its extension to "A ontology is an explicit, partial account of a conceptualization". For our intentions the Guarino's suggestion (Guarino, 1997) seems to be the most clearly: "An ontology is a logical theory that constrains the intended models of a logical language".

In the recent years an increasing interest in ontologies for many natural language applications has led to the creation of ontologies for different purposes and with different features. In (Guarino et al., 1999), also remarked in (Magnini et al., 2002), two main kinds of existing ontologies are differentiated, i.e. linguistic and formal ontologies. The first ones are large scale lexical resource, that cover most words of a language and describe the various word senses, providing at the same time an ontological structure based on semantic relationships among the word senses. On the other hand formal ontologies -or Aristotle's ones- classify all physical word objects in ten basic categories such as Substance, Quality, Quantity, Activity and so on -see (Sowa, 2000)-, according to their form assuming these as abstraction derived from sensory experiences, and so independently of the language used to describe them. They mainly difference between formal and linguistic ontologies is the degree of the concerned formalization.

For a smoothly interoperation among all kinds of agents involved in VEs a linguistic ontology applied to the powerful expression of the natural language is required. Its semantic network should restrict all possible interpretations within the information exchange process, leading back the used words to a predefined terminology -in case of Human Knowledge Exchange, which must be committed 
from all participants, or to a standard formalism -in case of both Human-MachineInteraction and Machine Data Exchange, which has to be application-based and well-structured in all interaction forms.

Different significant works focused on knowledge retrieval using the natural language have already been performed. They show, how the semantic relations of ontological networks -rather linguistic or formal- could significantly contribute to make progresses in this research field. Some of the most relevants are: The Natural Representation Project (Barley et al., 1997), The Ontolingua Server (Farquahar et al., 1996), Ontosaurus (Swartout et al., 1996), Ontologies for HTML (Luke et al., 1996), Ontologies for XML (Erdmann et al., 1999), Conceptual Indexing (Woods, 1997), Semantic Indexing with WordNet (Mihalcea et al., 2000) as well as (Gonzalo et al., 1998) and Web Indexing (Desmontils et al., 2001).

\section{APPLIED ONTOLOGY SOLUTIONS}

As mentioned before, the VE agents communicate at different knowledge representation levels. Thus, in order to enable interoperability in all three communication fields, shown in section 2, a translation process, composed of different translation and verification phases, is necessary. Figure 2 illustrates its course structure.

All knowledge forms with their variety of expressions, due to different language and cultural features and data forms as well, are first registered respectively in the Knowledge Connector \& Navigator $(\mathrm{KCN})$ and in the Data Connector \& Navigator (DCN). These provide knowledge and data interpretation, linking the possible intended meanings, resulting from a triple-phase analysis, described below:

- The first stage -the semiotic analysis- looks up all the used words in a vocabulary (LD: Linguistic Database) of predefined terminology, determines their root forms plus possible inflections, expands contractions, and finds the parts of speech.

- The second stage -the syntax analysis- uses grammar rules to compute a more or less parse tree (Sowa, 2000) (GTM: Grammar Translation Modules), which represents the syntax as a combination of phrases and sub phrases.

- The final stage -the semantic analysis- scans the parse three (AOD: Applied Ontology Database), translates it into a Petri-Net Model (PNG: Petri-Nets Generator) and verifies as well as validates the achievability of the presented model (Hölzlein, 1998).

The procedures described above are valid for all three interaction forms presented in section 2. However, the translation process for Machine Data Exchange is quite easier, since machines communicate at logical level and, thus, semiotic, syntax and semantic analysis extended to all cases of a natural language are not required. The use of translation modules, control of machine-based syntax form of the program languages and achievability verification of the corresponding Petri-Net model here play important roles.

In this concept, ontologies composes of LD and the AOD. The first one is an lexical reference system, like WordNet (Fellbaum, 1988), which organizes English nouns, verbs and adjectives into synonym set, each representing one underlying 
lexical concept. Different relations (i.e. Hyponymy, Meronymy, Antonymy and Morphological Relations) link the synonym sets. According to N. Guarino, we can define WordNet as Linguistic Ontology.

The second one is an ontology, which consists of classes, functions and relations, that uses variables for describing semantic cases, compatibility and terminological roles in a form that can be adapted to multiple knowledge languages. In the next section our prototype is briefly described.

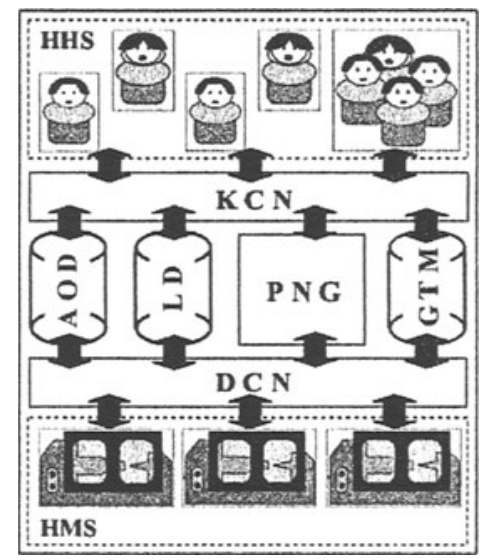

Figure 2 - Translation Process

\section{ONTOFILTER: A PROTOTYPE}

According to M. Uschold's methodology (Uschold, 1996), a linguistic ontology has been built for a variety of purposes within the automation technology domain (i.e. diagnostic, maintenance, correction of industrial robots (IR)). It includes the powerful structure of WordNet, merged together with a specialized linguistic ontology -a so-called Context Ontology- (Magnini et al., 2002). The first contains generic knowledge domain without specific coverage and the other focuses on a specific domain, providing sub-hierarchies of highly specialized concepts.

With the syntax and semantics of Ontolingua (Gruber, 1992) Classes have been defined such as Humans, Machines, Processes, Failures, Work Tools, Work Pieces and so on, in order to gather terms together in one group according to their special acquired role in the treated domain context. Also Relations among the coined Classes have been introduced. They are defined by constraints on their arguments and limit so the possible semantic combinations between them. An example of Classes and Relations is given below:

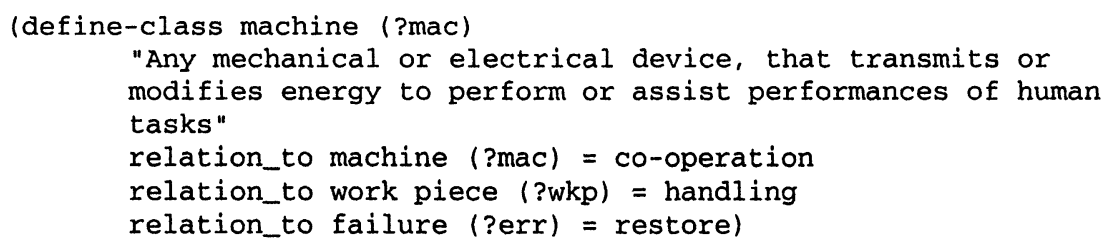




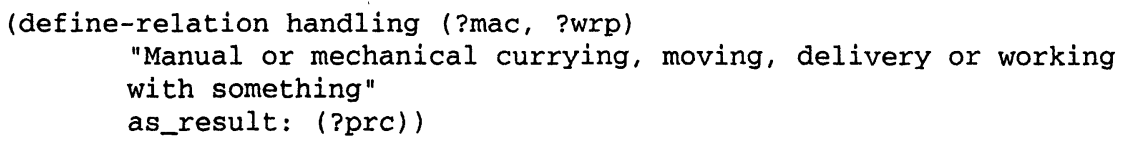

First experimental trial tests of this concept have been performed within a natural language interface (Figure 3). This allows standardization of the natural expression forms and, at the same time, translates the entered instruction in IR codes. The performed tests show interesting results, motivating the authors and other persons, involved in this project to proceed in this research field.

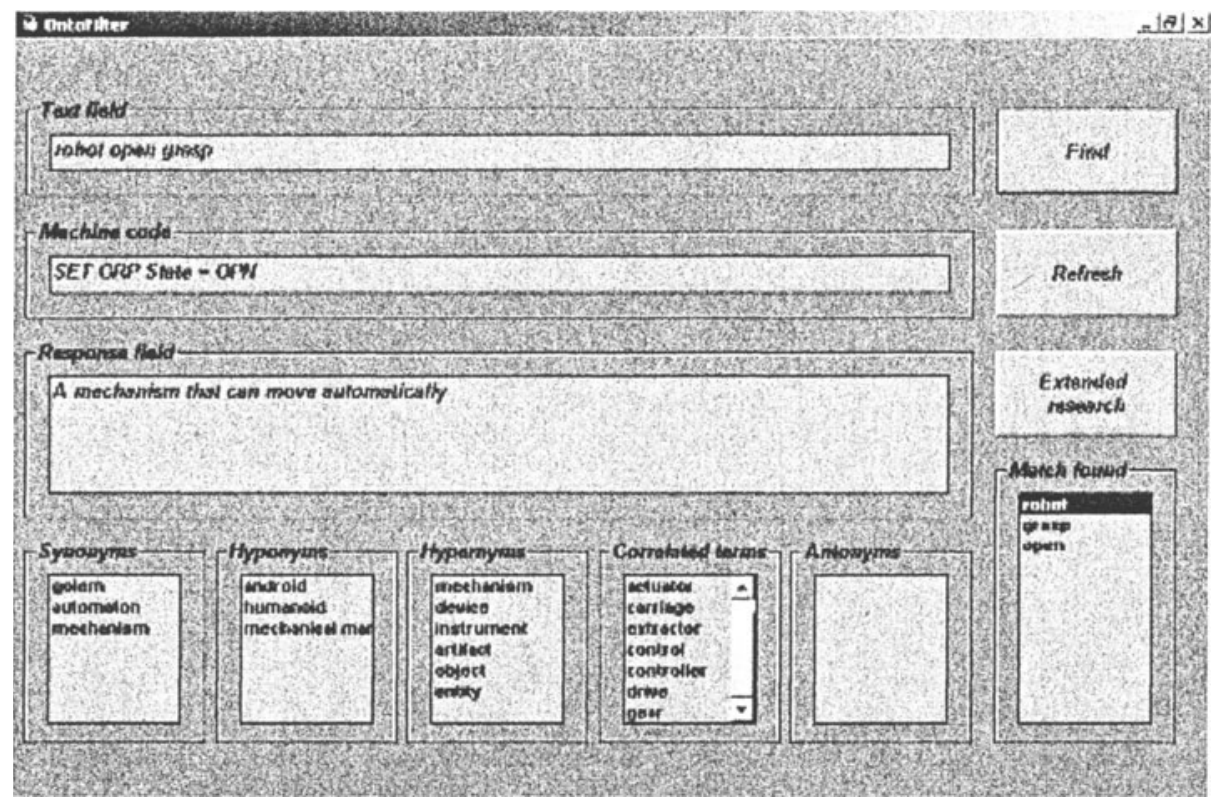

Figure 3 - Prototype Interface Structure

\section{Acknowledgements}

The project described in this paper is performed in the laboratory of the Department of Automation Technology of the Brandenburg University of Technology. For the project tests a KUKA Robot has been employed. We are special indebted to Mauro Alterio for his contribution to this work.

\section{REFERENCES}

1. Gebauer, J.; Segev, A.: "Assessing Internet-based Procurement to Support the Virtual Enterprise", ,"Virtual-Organization.net, Newsletter (2,3), September, 1998.

2. Guarino, N: „The Ontological Level“, In Philosophy and the Cognitive Science, R. Casati, B. Smith and G. White (ed.), Holder-Pichler-Tempsky, Vienna, 1994.

3. Sowa, John F.: „Knowledge Representation: Logica, Philosophical and Computational Foundations”, Brooks and Cole Ed., CA, USA, 2000. 
4. Zarli, A; Amar, Virginie: "Integrating STEP and CORBA for Applications Interoperability in the Future Virtual Enterprises Computer-based Infrastructures", in Proceedings of intelligent information systems, Bahamas, December 1997, pp 309-315.

5. Fowler, J. "STEP for Data Management, Exchange and Sharing “, Technology Appraisals 1995.

6. Object Management Group (OMG) : "The Common Object Request Broker Architecture and Specification (CORBA)", Revision 2.0, July, 1995 - (http://www.omg.org).

7. Van Eijnatten, F. M.; Vink, P.: „Partecipative Simulation in the PSIM Project“, in "Intelligent manufacturing through participation", Frans M. Van Eijnatten (ed.), The PSIM Consortium / TNO Arbeid, Hoofddorp, The Netherlands, March, 2002, pp. 9-19.

8. Yamatake Corp.: "Organisational Aspects of Human-Machine Coexisting System", in HUMACS Project Proposal Version 2.2, Intelligent Manufacturing System Program, October, 1996.

9. Guarino, N.; Masolo, C.; Vetere, G.: "OntoSeek: Content-Based Acess to the Web", in IEEE Intelligent System and Their Application. 14(3), 1999, pp. 70-80.

10. Barley, M.; Clark, P.; Williamson, K.; Woods, S.: "The Natural Rapresentation Project", in Proceedings of AAAI'97, Stanford University, AAAI Press, USA, 1997, pp. 1-8.

11. Farquhar, A.; Fikes, R., Rice, J.: „The Ontolingua Server: a Tool for Collaborative Ontology Construction", in Proceedings of KAW’96, November, 1996.

12. Swartout, B.; Patil, R., Knight, K.; Russ, T.: "Ontosaurus: A Tool for Browsing and Editing Ontologies"in Proceedings of KAW“96, November, Banff, Canada, 1996.

13. Woods, W. A.; Schmolze, J. G.: "The KL-ONE Family", Computer and Mathematics with Application 23:2-5, 1992, pp. 133-177.

14. McGuire, J. G.; Kuokka, D. R.; Weber, J. C., Tanenbaum, J. M; Gruber, T. R.; Olsen, G. R.: „Shade: Technology for Knowledge-Based Collaborative Engineering", in Journal of Concurrent Engineering: Applications and Research (CERA), 1(2), September, 1993.

15. Brachman, R. J.: „On the Epistemological Status of Semantic Networks”, In N. V. Findler (ed.), “Associative Networks: Representation and Use of Knowledge by Computers", Academic Press, 1979.

16. Guarino, N.: "Understanding, Building and Using Ontologies": International Journal of Human and Computer Studues (46), pp. 290-310, 1997.

17. Gruber, T. R.: „Toward principles for the design of ontologies used for knowledge sharing“, in International Journal of Human-Computer Studies, 43, 1995, pp. 907-928.

18. Magnini, B.; Speranza M.: "Marging Global and Specialized Linguistic Ontologies", in Proceedings of Ontolex 2002 Ontologies and Lexical Knowledge Bases, Simov K. (ed.), Workshop held in conjunction with LREC-2002, Las Palmas, Canary Islands, Spain, May 27-31, 2002, pp. 43-48.

19. Luke, S.; Spector, L.; Rager, D.: "Ontologie-based knowledge discovery on the Word-Wide-Web", in Proceedings of the AAAI'96, Workshop of Internet-based Information Systems, USA, 1996.

20. Erdmann, M.; Stuber, R.: „Ontologies as conceptual models for XML documents”, in Proceedings of the twelfth Workshop on Knowledge Acquisition, Modeling and Management (KAW'99), Voyager Inn, Banff, Canada, October, 1999.

21. Woods, W. A.: "Conceptual Indexing: A better way to organize knowledge", Technical Report, SUN Technical Reposit TR-96-61, 1997.

22. Mihalcea, R.; Moldovan, D.: "Semantic Indexing using WordNet sences", in Proceedings of the ACL'00 Workshop, Hong Kong, October, 2000.

23. Gonzalo, J.; Verdejio, F.; Chugur, Cigarran, J.: "Indexing with WordNet synsets can improve text retrieval", in S. Harabagiu (ed.), Proceedings of the Workshop of Usage of WordNet in Natural Language Processing Systems, Montreal, Canada, August, 1998.

24. Desmontils, E.; Jacquin, C.: "Indexing a web site with a terminology oriented ontology" , in Proceedings of SWWS'01 International Semantic Web Working Symposium, Standford University, USA, July-August, 2001.

25. Guarino, N.; Giarretta, P.: "Ontologies and Knowledge Bases: Towards Terminological Clarification", in Towards Very Large Knowledge Bases: Knowledge Building and Knowledge Sharing, N. Mars (ed.), IOS Press, Amsterdam, 1995, pp. 25-32.

26. Fellbaum, C.: "WordNet: An Elektronik Lexical Database", MIT Press, USA, 1998.

27. Hölzlein, M.; Filkorn, T.; Warkentin, P.: „Erfahrungen mit der formalen Verifikation von Zustandsgraphen-Programmen“, VDI-Bericht Nr.1397, GMA-Kongress, Ludwisburg, Germany, June, 1998.

28. Uschold, M.: „Building Ontologies: Towards a Unified Methodology“, in Proceedings of $16^{\text {th }}$ Expert System Conference, UK, December, 1996.

29. Gruber, T. R.: „Ontolingua: Amechanism to support portable ontologies“, Standford University, Knowledge Systems Laboratory, Technical Report KSL-91-66, March, 1992. 